\title{
A Compact Experimental Planar Antenna with a USB Connector for Mobile Phone Application
}

\author{
Cheng-Hung Lin and Kwong-Kau Tiong \\ Department of Electrical Engineering, National Taiwan Ocean University, No. 2, Beining Road, Jhongjheng District, \\ Keelung City 202, Taiwan \\ Correspondence should be addressed to Cheng-Hung Lin; josephlin1027@gmail.com
}

Received 4 February 2015; Accepted 14 July 2015

Academic Editor: Ercument Arvas

Copyright (C) 2015 C.-H. Lin and K.-K. Tiong. This is an open access article distributed under the Creative Commons Attribution License, which permits unrestricted use, distribution, and reproduction in any medium, provided the original work is properly cited.

\begin{abstract}
A practical antenna design combined with a universal serial bus (USB) connector in close vicinity is proposed. In the proposed arrangement, the antenna unit consisted of two planar inverted $\mathrm{F}$ antennas (PIFAs) placed on the two sides of the USB connector. The antenna is located at the bottom of the mobile phone to avoid the crowded space on the top side of the phone where various mobile phone accessories are usually assigned. A diplexer is incorporated in the unit to alleviate the adverse effect of the metal USB connector on the radiating efficiency of the antenna. A prototype antenna was fabricated and tested and showed good coverage for GSM850/900/1800/1900, UMTS2100, and LTE700/2500 multibands operation. The overall performances demonstrated the good design of the proposed unit for mobile phone application.
\end{abstract}

\section{Introduction}

With the rapid development of wireless communication technology, the studies on multiband antennas for mobile phone applications [1] are demanded. Wide bandwidth and compact structure are important requirements for the antenna design. The planar antennas can provide wide operating bands for wireless wide area network (WWAN) [2]. The PIFA is generally implemented [3], and it can be easily integrated onto the mobile phone [4].

Several developments on the design of promising internal antenna covering the WWAN/LTE operations in the 824$960 / 1710-2690 \mathrm{MHz}$ bands for smartphone application have been demonstrated $[5-8]$. In $[5,6]$, the antenna occupied an area, respectively, of $435 \mathrm{~mm}^{2}(15 \times 29)$ and $375 \mathrm{~mm}^{2}$ $(15 \times 25)$, while that of [7] implemented a compact T-slit monopole antenna with slotted ground plane covering 824$960 / 1710-2170 \mathrm{MHz}$ bands occupying an area of $470 \mathrm{~mm}^{2}$ (10 $\times 47) \mathrm{mm}^{2}$. In [8] a coupled-fed antenna with two symmetrical printed meandered inductive strips as two distributed inductors covering Global System for Mobile Communication (GSM, 824-894 MHz and 880-960 MHz)/Digital Communication System (DCS, 1710-1880 MHz)/Personal Communication System (PCS, 1850-1990 MHz), Universal Mobile
Telecommunication System (UMTS, 1920-2170 MHz), and Long Term Evaluation (LTE, $704-746 \mathrm{MHz}$ and $2500-$ $2690 \mathrm{MHz}$ ) bands operation for the internal mobile phone application was proposed with the antenna occupying an area of $450 \mathrm{~mm}^{2}(15 \times 30)$.

More recent works on the miniaturization of the antenna area have also been carried out by proposing a novel bending strip to reduce the effective width of the antenna to give a small antenna area of $375 \mathrm{~mm}^{2}(15 \times 25)$ in [9] and $450 \mathrm{~mm}^{2}$ $(15 \times 30)$ in [10]. In the literature, the gains and radiation efficiencies at the respective operating bands are quite high. For instance, in [10], for the lower band of GSM850/900 (824$960 \mathrm{MHz}$ ), the antenna gain is $0.03-0.89 \mathrm{dBi}$ with radiation efficiency of about $50 \%-65 \%$. For the upper bands of DCS/ PCS, UMTS2100, and LTE2300/2500, which covered a frequency range of $1710-2690 \mathrm{MHz}$, the obtained antenna gain is $0.56-3.13 \mathrm{dBi}$ with corresponding radiation efficiency larger than $65 \%$. However, these values were achieved without considering the more realistic circumstances of the presence of other accessories such as USB connector and camera lens, which would depreciate the performance of the radiator. The aforementioned issue is always ignored in most studies [510] on the performance of compact size antenna for slim 
smart phone application. In this study, particular attention is being taken in the design of the radiator to include the effect of metal accessory, namely, the USB connector, in close proximity.

In the present proposed design, we have also considered the particular aspect of a commercial smartphone in which the top side of the phone is usually overcrowded with many accessories such as camera, audio jack, and receiver $[5,6]$. Therefore, it is proposed that the antennas together with a USB connector, typical size $350 \mathrm{~mm}^{3}(10 \times 7 \times 5)$, are to be colocated on the bottom side of the mobile phone. Two noground regions of areas $150 \mathrm{~mm}^{2}(15 \times 10)$ and $250 \mathrm{~mm}^{2}(25$ $\times 10$ ) located on two sides of the USB are available for coating the antenna radiators. This particular arrangement can be easily implemented in a practical smart phone and also ensured that the radiator unit and the USB connector have no crossover region which would otherwise degrade the radiation efficiency of the antenna. The antennas were designed to cover the GSM850/900/1800/1900, UMTS2100, and LTE700/ 2500 bands. Furthermore, antenna placed at the bottom side of the mobile phone also has the inherent advantage of reduced phantom effect and hence a lower effective SAR.

The antenna characteristics were simulated using Ansoff's HFSS simulation software. The antenna measurements were performed in a far-field anechoic chamber equipped with ETS-Lindgren AMS-8500 Antenna Measurement System. The resonance frequency and input impedance of the antenna were optimized. The bandwidth referring to VSWR value of $3: 1$ demonstrated good coverage over 700-1000, 1700-2200, and $2500-2700 \mathrm{MHz}$ range. The simulated and measured results including return loss, gain, and radiation efficiency were presented and discussed.

\section{Antenna Design}

The antenna unit consisted of two radiating elements located at the bottom side of the mobile phone and separated by a USB connector. The two radiators are constructed of copper and coated on a plastic carrier which is made of $1 \mathrm{~mm}$ thick Acrylonitrile Butadiene Styrene (relative permittivity 3.0 and conductivity $0.01 \mathrm{~S} / \mathrm{m}$ ). The FR4 substrate of the mobile phone is $60 \mathrm{~mm} \times 120 \mathrm{~mm} \times 0.8 \mathrm{~mm}$ (relative permittivity 4.4 and conductivity $0.005 \mathrm{~S} / \mathrm{m}$ ). One radiator is for the GSM850/900 and LTE700 bands; and another one is for DCS/PCS, UMTS2100, and LTE2500 bands. A model DPX202690DT diplexer manufactured by TDK Corporation, which has a low insertion loss of $0.24 \mathrm{~dB}$ from 704 to $960 \mathrm{MHz}, 0.38 \mathrm{~dB}$ from 1710 to $2170 \mathrm{MHz}$, and $0.83 \mathrm{~dB}$ from 2170 to $2690 \mathrm{MHz}$, was used in the circuit board to combine the two signals of low and high bands. The practical internal antenna design of compact size is for multiband operation and used in 2G/3G/4G communication system [11, 12]. In order to enhance the antenna performance, two ground regions are removed from the printed circuit board under the antenna area. The two no-ground regions have areas of $150 \mathrm{~mm}^{2}(15 \times 10)$ and $250 \mathrm{~mm}^{2}(25 \times 10)$. The ground area of $70 \mathrm{~mm}^{2}(10 \times 7)$ under the USB connector is kept intact. For practical application, the dimension set for compact mobile

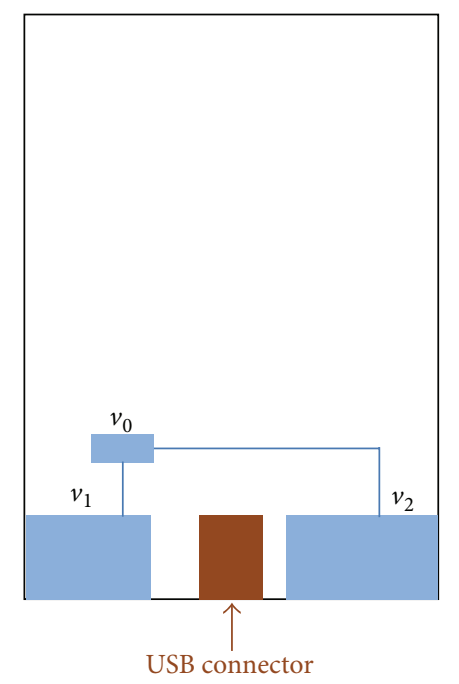

FIGURE 1: Geometry of the proposed antenna of the mobile phone for multibands operation.

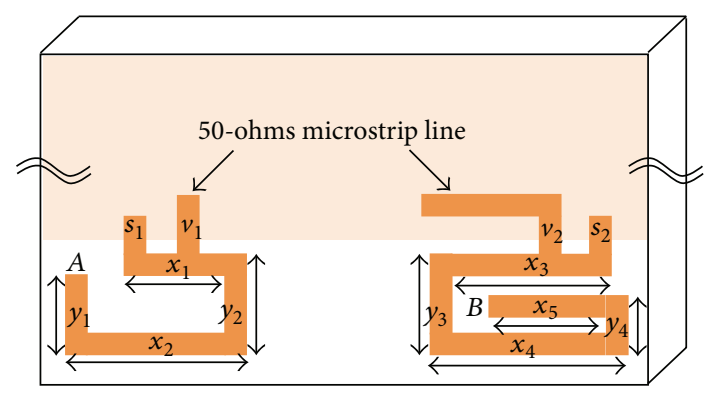

FIGURE 2: The practical prototype antenna for multibands operation.

phone design is reasonable by comparing to the sizes of the literature [5-9]. The geometry of the proposed planar antenna located on the bottom side of the mobile phone is shown in Figure 1. The two internal antennas occupied a total area of $400 \mathrm{~mm}^{2}$, which is attractive for slim mobile phone applications. With a unit height of $6 \mathrm{~mm}$ (USB height of $5 \mathrm{~mm}$ and the thickness of the PCB at $1 \mathrm{~mm}$ ), the setup is well suited for mobile phone thickness of less than $10 \mathrm{~mm}$.

In Figure 1, the port $v_{1}$ is a feed point of radiator for high band and port $v_{2}$ is for low band. The two feeding ports are connected to a diplexer, which served to combine the signal with the RF port (point $v_{0}$ ). The PIFA radiator has a shorting pad. The slot of the radiator is used for attaining the effective length of the required resonance frequency. The feeding port is connected to a 50 -ohm microstrip line for testing.

The practical prototype antenna for multiband operation is shown in Figure 2. The length $x_{1}+y_{2}+x_{2}+y_{1}$ from point $s_{1}$ to point $A$ is $\sim 40 \mathrm{~mm}$ corresponding to a quarter wavelength at $1900 \mathrm{MHz}$. The length $x_{3}+y_{3}+x_{4}+y_{4}+x_{5}$ from point $s_{2}$ to point $B$ is $\sim 80 \mathrm{~mm}$ which is about a quarter wavelength at $900 \mathrm{MHz}$. The photograph of the fabricated unit containing the high and low band antennas with a USB connecter is shown in Figure 3. 
TABLE 1: Measured antenna gain and efficiency of the proposed antenna at $v_{0}$ port.

\begin{tabular}{lcccccccccccc}
\hline Frequency $(\mathrm{MHz})$ & 700 & 800 & 900 & 1000 & 1700 & 1800 & 1900 & 2000 & 2100 & 2200 & 2500 & 2700 \\
\hline Gain $(\mathrm{dBi})$ & -2.1 & -1.4 & -1.1 & -1.5 & -1.1 & -0.9 & -0.6 & -0.8 & -1.2 & -1.4 & -1.3 & -1.2 \\
\hline Eff. $(\%)$ & 34 & 39 & 41 & 38 & 36 & 39 & 43 & 37 & 36 & 34 & 46 & 42 \\
\hline
\end{tabular}

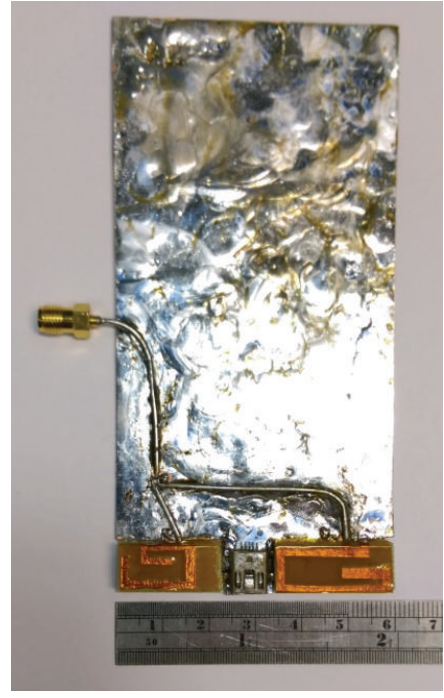

Figure 3: The fabricated model of the proposed antenna.

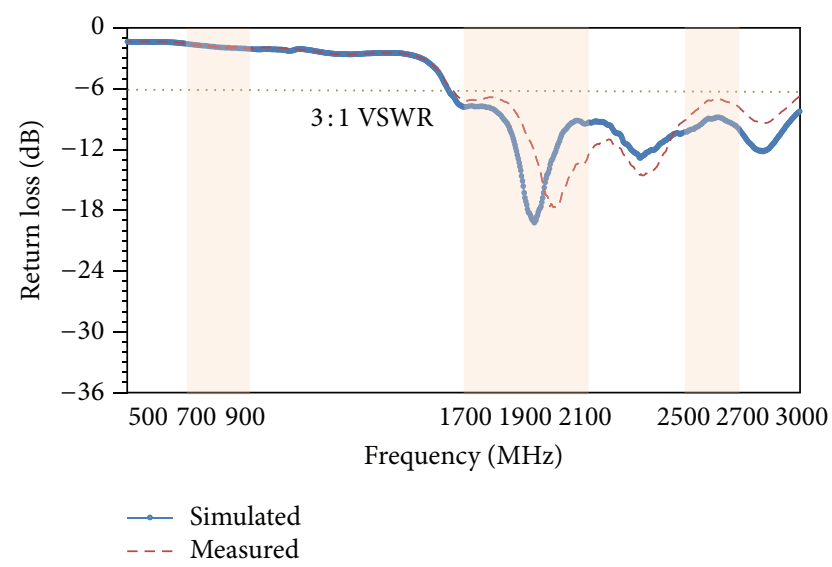

FIGURE 4: Simulated and measured VSWR of the proposed antenna at $v_{1}$ port.

\section{Results and Discussions}

The practical antenna unit containing the USB as shown in Figure 3 was fabricated and tested. The simulated and measured results of the return loss of $v_{1}$ port for the high band and $v_{2}$ port for the low band are shown in Figures 4 and 5, respectively.

A comparison of the results as depicted in Figures 4 and 5 shows good agreement both for the high and low bands. The signals of $v_{1}$ and $v_{2}$ are combined with $v_{0}$ by the

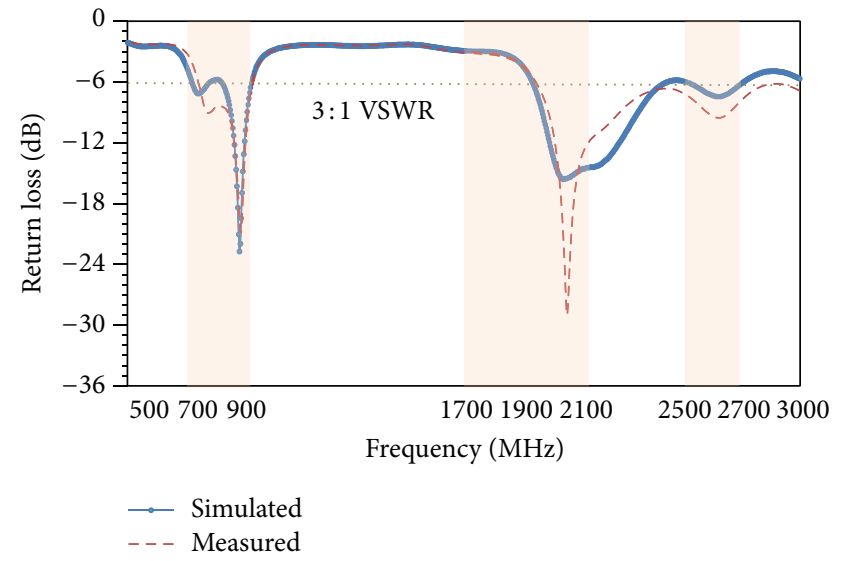

FIGURE 5: Simulated and measured VSWR of the proposed antenna at $v_{2}$ port.

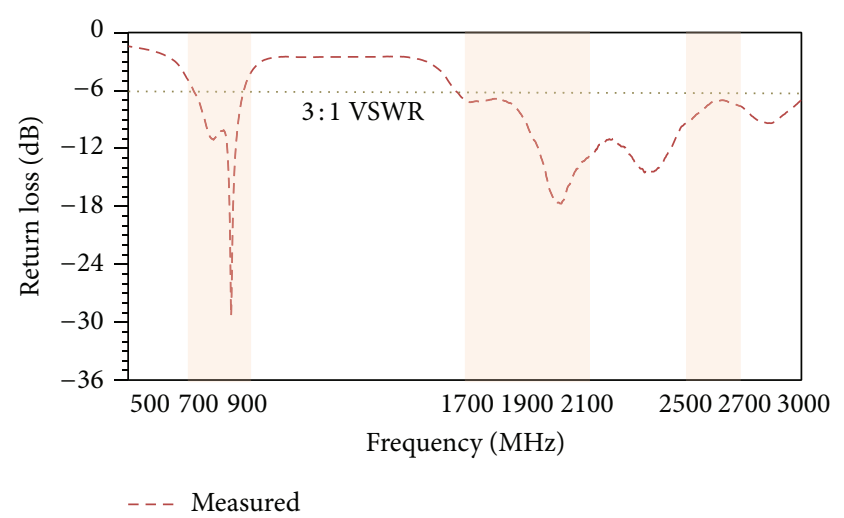

FIgURE 6: Measured VSWR of the proposed antenna at $v_{0}$ port.

diplexer. The return loss of $v_{0}$ port, which includes the insertion loss of the diplexer, is shown in Figure 6 and indicated good performance both in the low and high bands, by referring to VSWR value of lower than $3: 1$. The bandwidth which ranged from 700 to $1000 \mathrm{MHz}$ covered the GSM850/ 900 and LTE700 bands, from 1700 to $2200 \mathrm{MHz}$ covered the DCS/PCS and UMTS2100 bands, and from 2500 to $2700 \mathrm{MHz}$ covered the LTE2500 band [9]. The measured and simulated optimal antenna peak gains at $v_{1}$ and $v_{2}$ are shown in Figures 7 and 8, respectively. The simulated and measured results also showed excellent match. The measured gain and efficiency at $v_{0}$ which includes the insertion loss of the diplexer are listed in Table 1. For the low band (700$1000 \mathrm{MHz}$ ), the antenna gain varies from -1.1 to $-2.1 \mathrm{dBi}$ and 


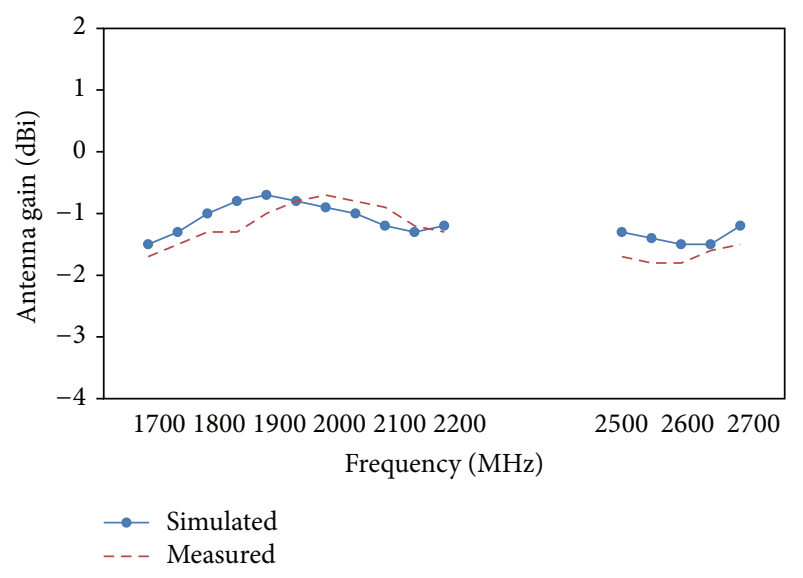

FIGURE 7: Simulated and measured antenna gain of the proposed antenna at $v_{1}$ port.

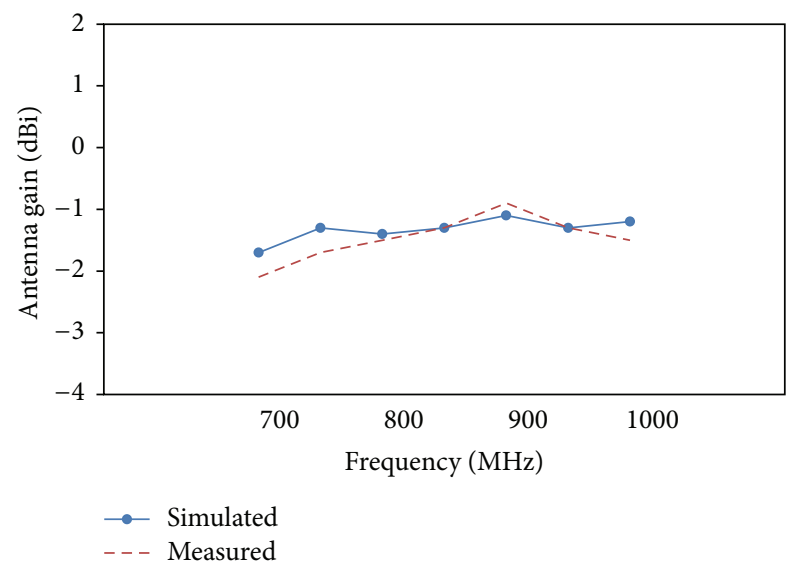

FIGURE 8: Simulated and measured antenna gain of the proposed antenna at $v_{2}$ port.

radiation efficiency is about $34-41 \%$; for the high band (1700$2700 \mathrm{MHz}$ ), the antenna gain varies from -0.6 to $-1.4 \mathrm{dBi}$ and radiation efficiency is about $34-43 \%$. The gain performances in the low and high bands indicated good coverage of the GSM850/900/1800/1900, UMTS2100, and LTE700/2500 for practical application in mobile phones.

The lower values for the gain and radiation efficiency by comparing to the results of the literature [5-10] reflect the more realistic situation of the present work with the presence of a USB in close vicinity. Moreover, it is also noted that if a USB dongle is in place, further degradation of $\sim 0.5 \mathrm{~dB}$ at the low band and $\sim 1 \mathrm{~dB}$ at high bands will occur. Nevertheless, this will not affect the overall good performance of the antenna unit.

The antenna characteristics of the radiation pattern were studied as well. The measured radiation patterns for 900 , 1800 , and $2500 \mathrm{MHz}$ are shown in Figures 9, 10, and 11, respectively. For the radiation pattern at $900 \mathrm{MHz}$, it shows a dipole-like pattern with good omnidirectional radiation, which indicates the stable radiation characteristic over the
TABLE 2: SAR tissue data.

\begin{tabular}{lcccccc}
\hline SAR & \multicolumn{3}{c}{ Head tissue liquid } & \multicolumn{3}{c}{ Body tissue liquid } \\
\hline Frequency (MHz) & 900 & 1950 & 2450 & 900 & 1950 & 2450 \\
Relative permittivity & 41.5 & 40 & 39.2 & 55 & 53.3 & 52.7 \\
Conductivity (S/m) & 0.97 & 1.4 & 1.8 & 1.05 & 1.52 & 1.95 \\
\hline
\end{tabular}

TABLE 3: Measured 1-g SAR data.

\begin{tabular}{lcccc}
\hline Frequency $(\mathrm{MHz})$ & 900 & 1800 & 2100 & 2500 \\
\hline 1-g SAR $(\mathrm{mW} / \mathrm{g})$, head & 0.62 & 1.07 & 1.24 & 1.04 \\
\hline 1-g SAR (mW/g), body & 0.31 & 0.65 & 0.78 & 0.66 \\
\hline
\end{tabular}

antenna's lower band. The radiation patterns at 1800 and $2500 \mathrm{MHz}$ show more variations. The variations are caused by the size of the ground plane which is comparable to the working wavelength of the high band. Nevertheless, the overall radiation patterns indicated reasonable omnidirectional characteristics for both the low and high bandwidths.

The 1-g SAR of the proposed antenna was also measured using DASY5 system manufactured by SPEAG. The head and body tissue liquid information provided by SPEAG are listed in Table 2. The measurements were taken with the fabricated unit placed close to the phantom ear with zero distance. The SAR results tested by an input power of $23 \mathrm{dBm}$ for 900,1800 , 2100 , and $2500 \mathrm{MHz}$ are shown in Table 3 . The test shows that the SAR of the present design is well within the limit of $1.6 \mathrm{~mW} / \mathrm{g}$ for the $1-\mathrm{g}$ head tissue.

\section{Conclusion}

A practical multiband planar antenna with a USB connector has been proposed for mobile phone applications. The resonant modes are formed by two wide operating bands for the low and high bands to cover GSM850/900/1800/1900, UMTS2100, and LTE700/2500 operation. The obtained results including VSWR, gain, efficiency, and radiation pattern were presented. The specific absorption rate (SAR) of the antenna design was also measured. The proposed antenna design showed high efficiency with low SAR value. The bandwidth of the proposed antenna makes it very suitable for $2 \mathrm{G}, 3 \mathrm{G}$, and $4 \mathrm{G}$ mobile communication applications.

\section{Conflict of Interests}

The authors declare that there is no conflict of interests regarding the publication of this paper.

\section{Acknowledgment}

The authors acknowledge the Antenna Department of HTC, Taiwan, for the support of the wireless technique and measurement environment. 


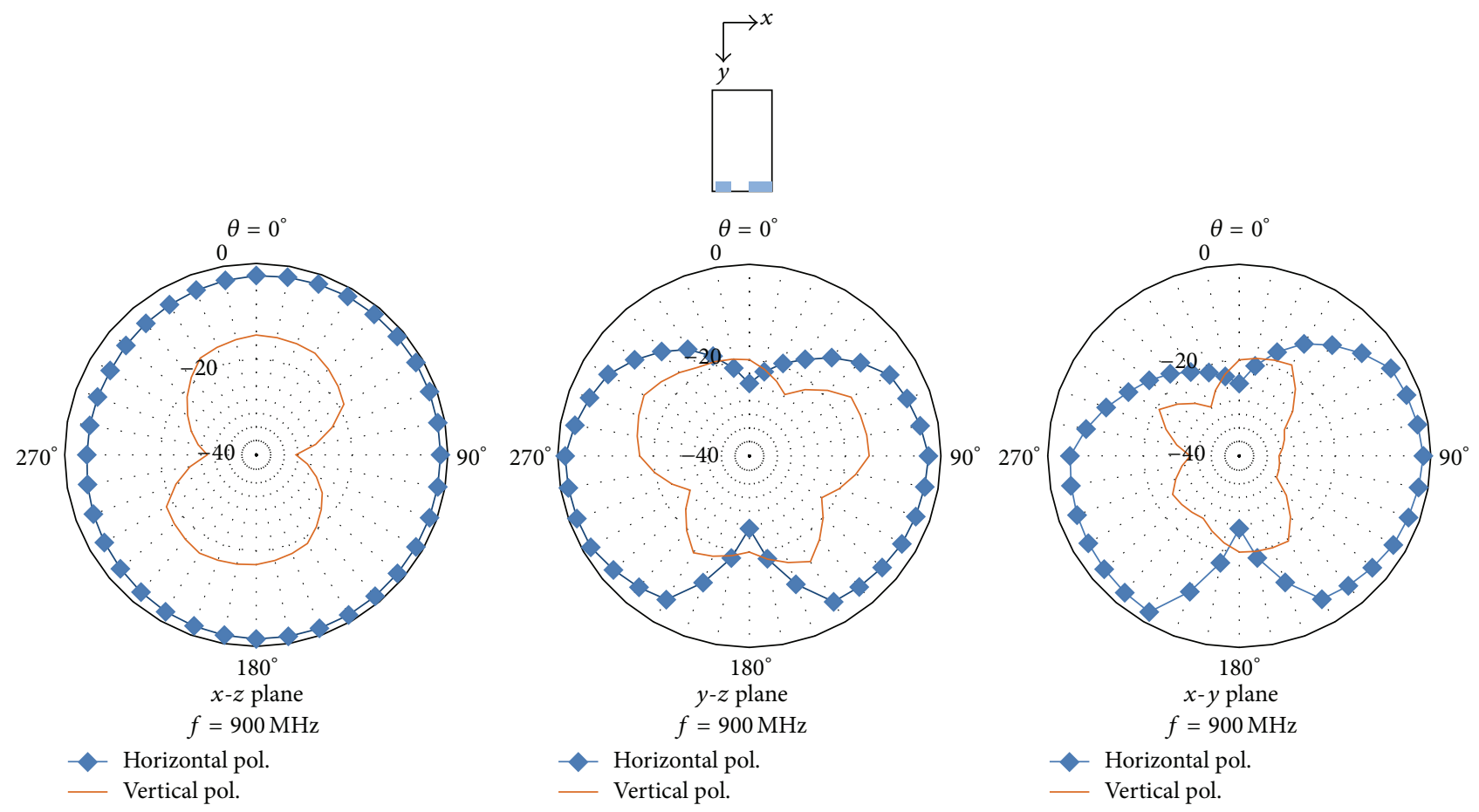

FIGURE 9: Radiation pattern of the proposed antenna at $900 \mathrm{MHz}$.

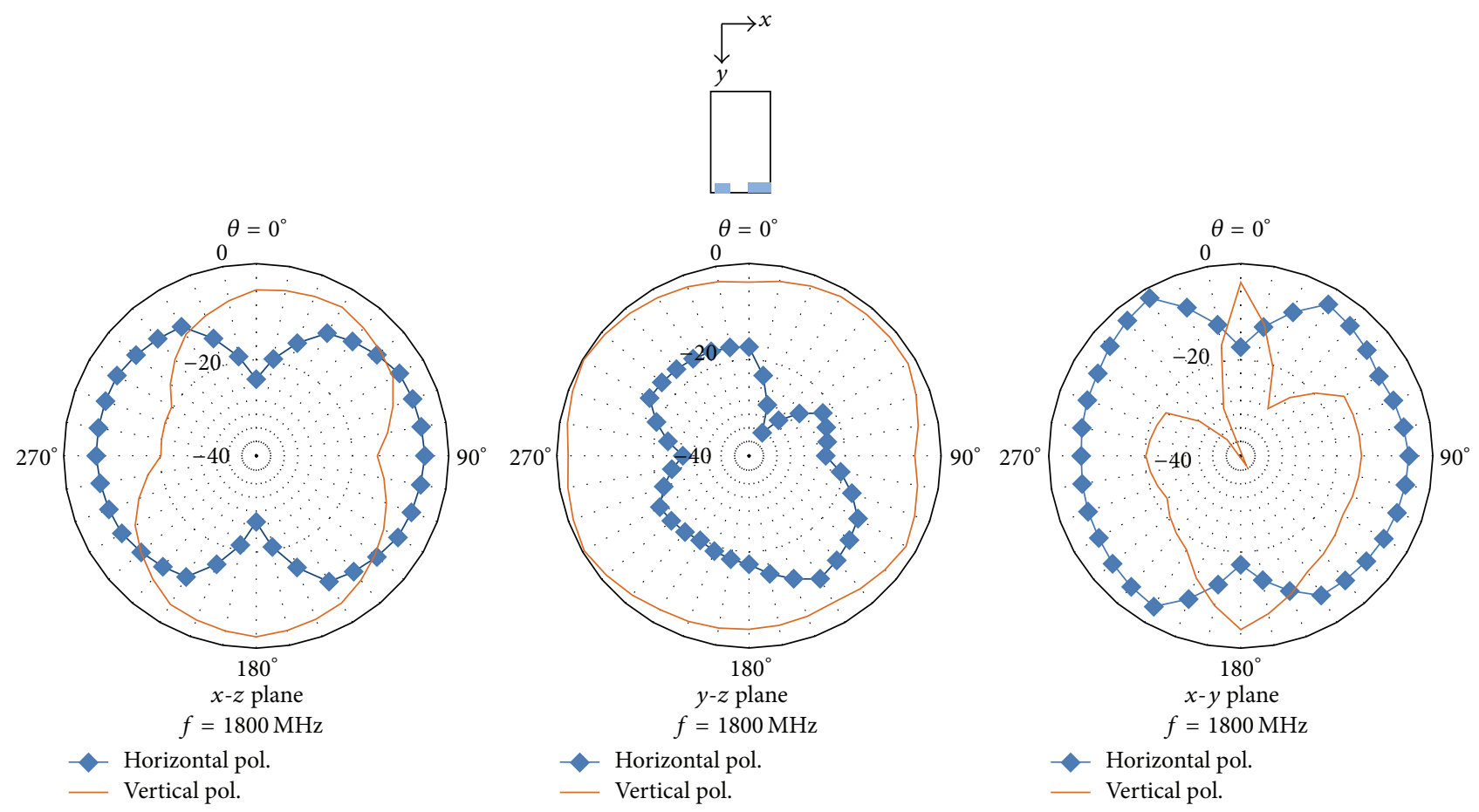

FIGURE 10: Radiation pattern of the proposed antenna at $1800 \mathrm{MHz}$. 


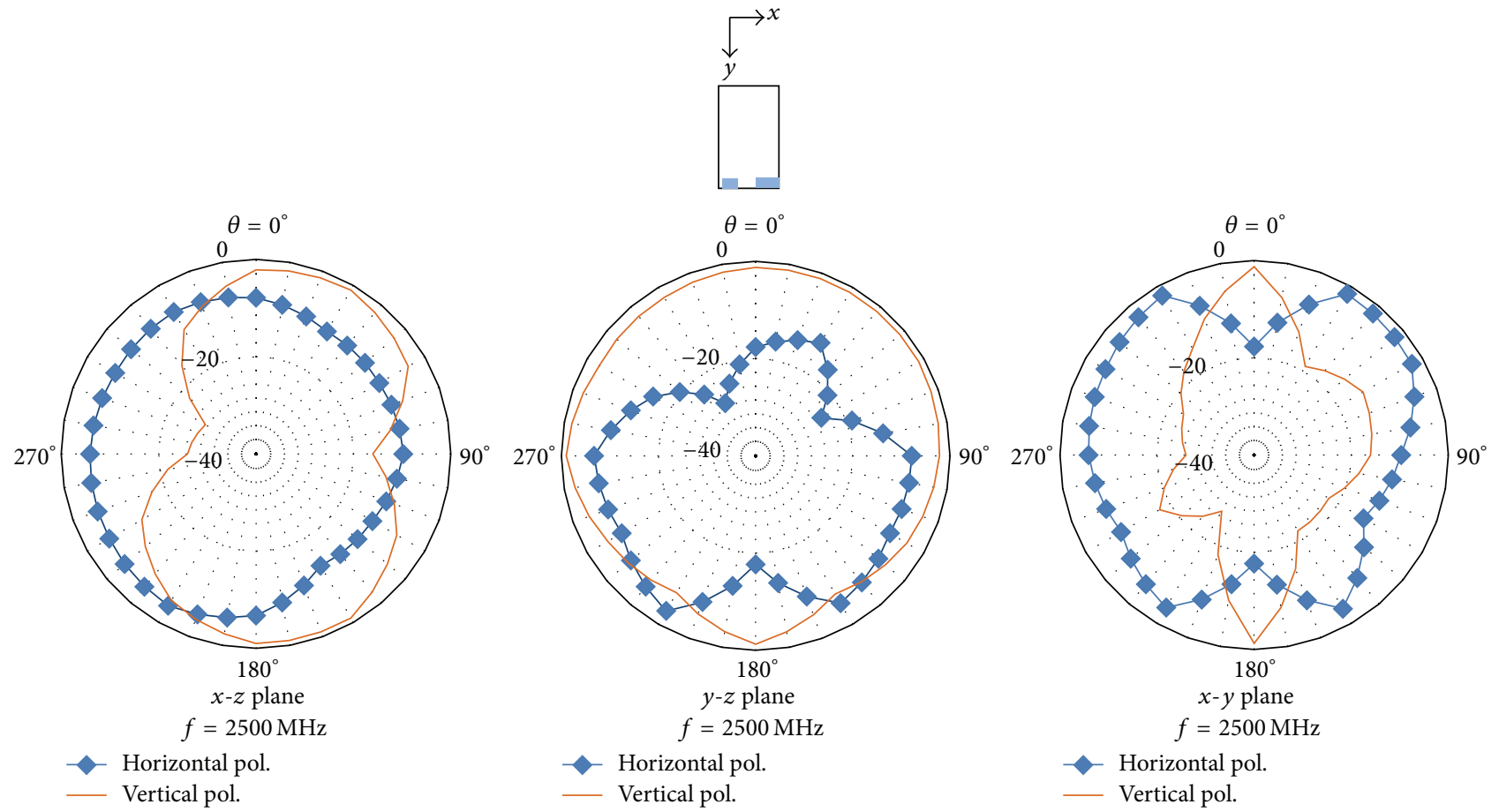

FIGURE 11: Radiation pattern of the proposed antenna at $2500 \mathrm{MHz}$.

\section{References}

[1] G. Y. Chen, J. S. Sun, S. Y. Huang, Y. D. Chen, C. H. Lin, and J. Y. Yang, "Mobile handset measurement for wireless system networking," in Proceedings of the China-Japan Joint Microwave Conference (CJMW '06), pp. 698-701, Chengdu, China, August 2006.

[2] K. L. Wong, Planar Antennas for Wireless Communications, John Wiley \& Sons, 2003.

[3] C. R. Rowell and R. D. Murch, "A compact PIFA suitable for dual-frequency 900/1800-MHz operation," IEEE Transactions on Antennas and Propagation, vol. 46, no. 4, pp. 596-598, 1998.

[4] D. Kraus and R. J. Marhefka, Antennas for All Applications, McGraw-Hill, 2002.

[5] Y.-L. Ban, C.-L. Liu, J. L.-W. Li, and R. Li, "Small-Size wideband monopole with distributed inductive strip for sevenBand WWAN/LTE mobile phone," IEEE Antennas and Wireless Propagation Letters, vol. 12, pp. 7-10, 2013.

[6] K.-L. Wong, M.-F. Tu, C.-Y. Wu, and W.-Y. Li, "On-board 7-band WWAN/LTE antenna with small size and compact integration with nearby ground plane in the mobile phone," Microwave and Optical Technology Letters, vol. 52, no. 12, pp. 2847-2853, 2010.

[7] C.-L. Liu, Y.-F. Lin, C.-M. Liang, S.-C. Pan, and H.-M. Chen, "Miniature internal penta-band monopole antenna for mobile phones," IEEE Transactions on Antennas and Propagation, vol. 58, no. 3, pp. 1008-1011, 2010.

[8] Y.-L. Ban, Y.-F. Qiang, Z. Chen, K. Kang, and J. L.-W. Li, "Lowprofile narrow-frame antenna for seven-band WWAN/LTE smartphone applications," IEEE Antennas and Wireless Propagation Letters, vol. 13, pp. 463-466, 2014.
[9] Y.-L. Ban, C.-L. Liu, Z. Chen, J. L.-W. Li, and K. Kang, "Smallsize multiresonant octaband antenna for LTE/WWAN smartphone applications," IEEE Antennas and Wireless Propagation Letters, vol. 13, pp. 619-622, 2014.

[10] Y.-L. Ban, C.-L. Liu, J. L.-W. Li, J. Guo, and Y. Kang, "Small-size coupled-fed antenna with two printed distributed inductors for seven-band WWAN/LTE mobile handset," IEEE Transactions on Antennas and Propagation, vol. 61, no. 11, pp. 5780-5784, 2013.

[11] K.-L. Wong and C.-H. Huang, "Bandwidth-enhanced internal PIFA with a coupling feed for quad-band operation in the mobile phone," Microwave and Optical Technology Letters, vol. 50, no. 3, pp. 683-687, 2008.

[12] R. Borowiec and P. M. Słobodzian, "A miniaturized antenna for 2G/3G frequency-band applications," Microwave and Optical Technology Letters, vol. 48, no. 2, pp. 399-402, 2006. 

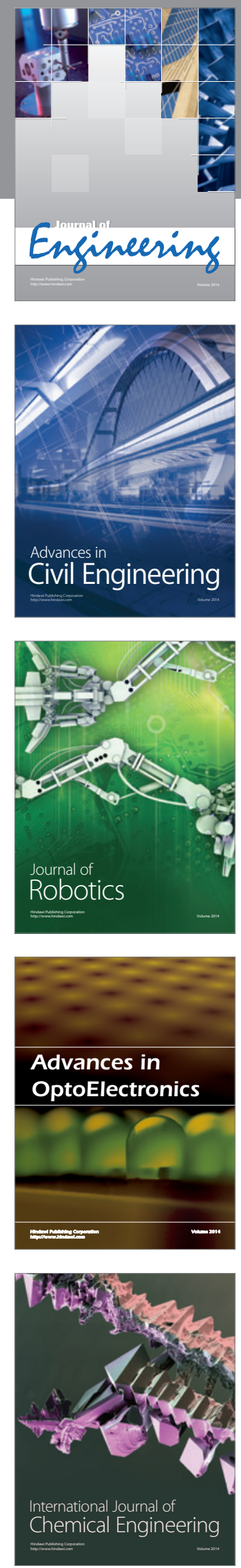

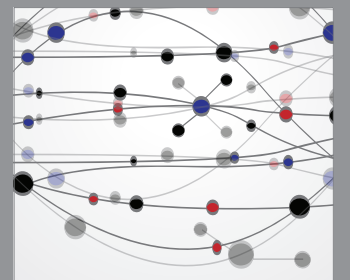

The Scientific World Journal
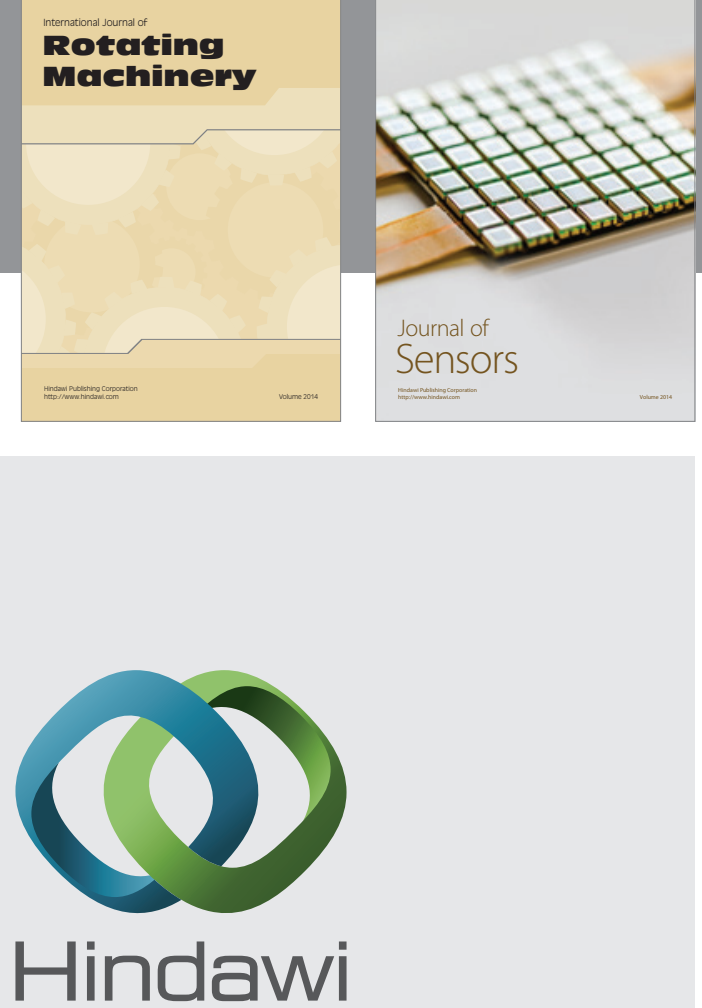

Submit your manuscripts at http://www.hindawi.com
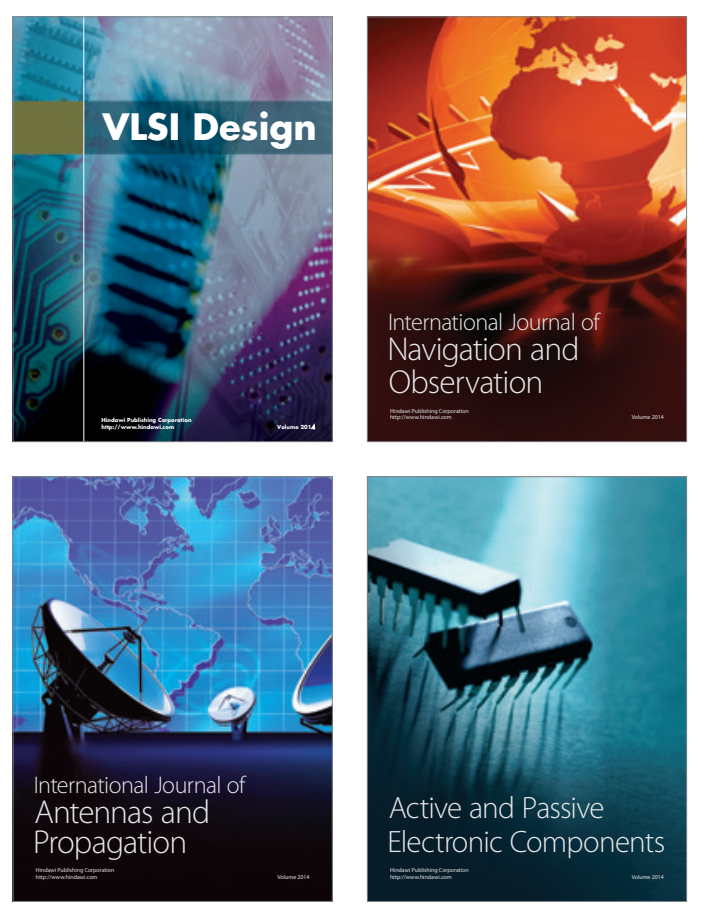
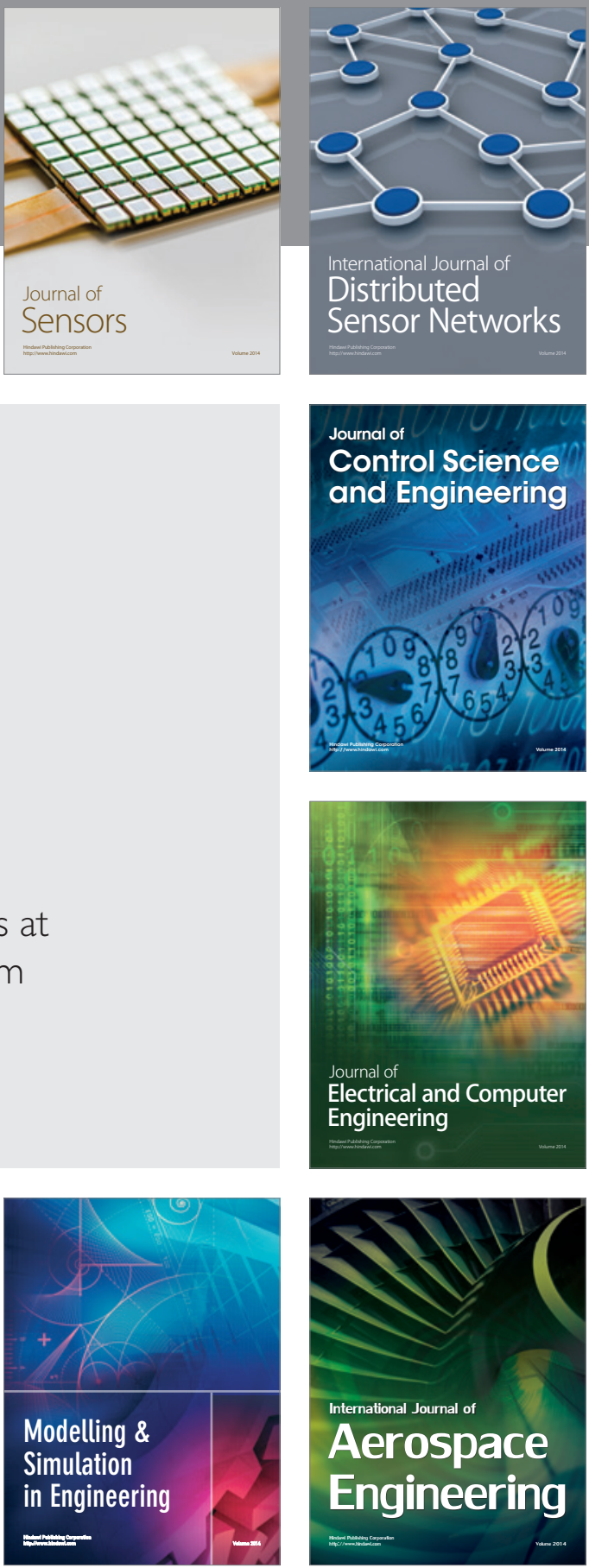

Journal of

Control Science

and Engineering
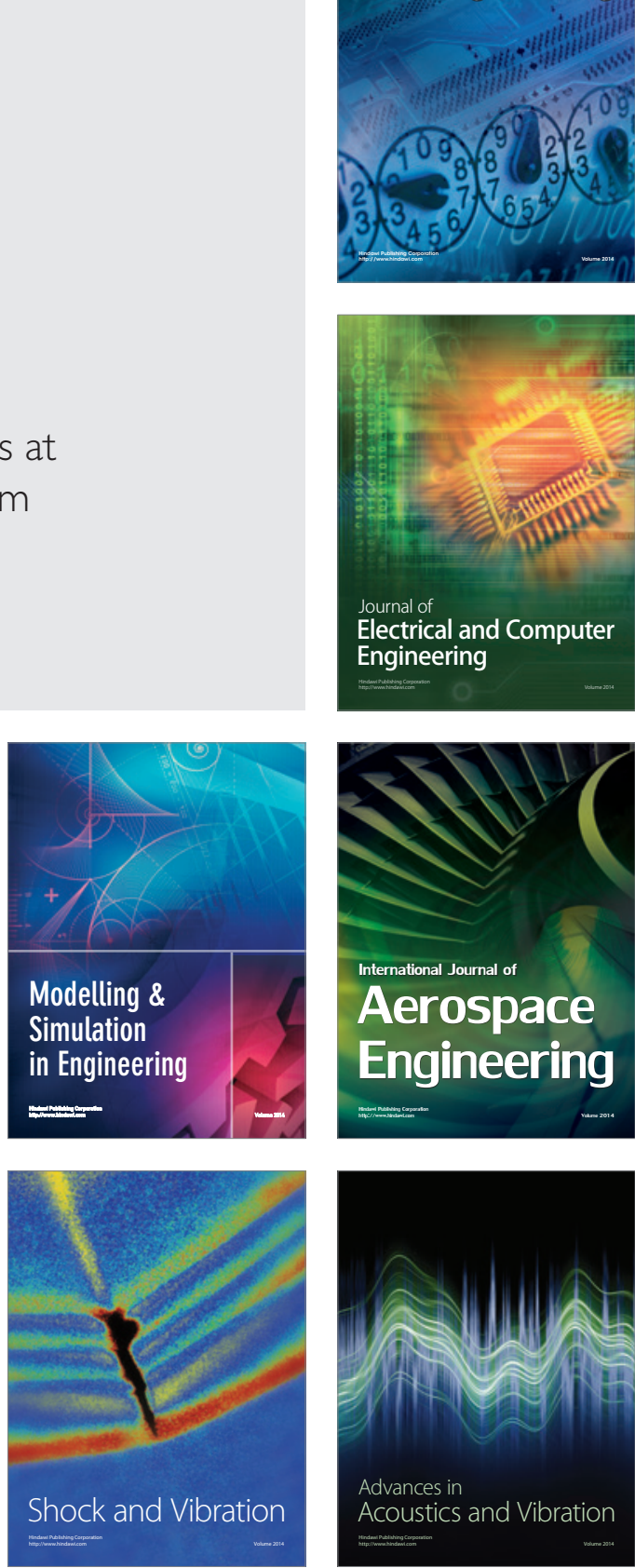